\title{
The Causal Relationship of Job Stressors, Job Calling and Job Burnout in Non-academic Staff of Faculties of Hamadan University of Medical Sciences
}

\author{
Bahram Tahmacbi $^{1}$ (D), Mahdi Zare Bahramabadi ${ }^{2 *}$ iD, Mahshid Izadi ${ }^{3}$ Hamide Abdolhoseini $^{4}$
}

1. PhD Student, Department of Education Science and Counseling, Faculty of Psychology, Central Tehran Branch, Islamic Azad University, Tehran, Iran

2. Institute for Research and Development in the Humanitis, SAMT, Tehran, Iran

3. Assistant Professor, Department of Education, Faculty of Psychology, Central Branch, Islamic Azad University, Tehran, Iran

4. $\mathrm{PhD}$ of Career Counseling, University of Isfahan, Isfahan, Iran

\section{Article Info \\ Received: 2020/02/12; \\ Accepted: 2020/03/01; \\ ePublished: 2020/03/26 \\ do \\ 10.30699/jergon.7.4.72 \\ Use your device to scan and read the article online

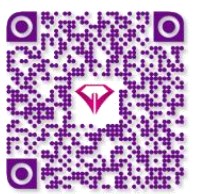

Corresponding Author Mehdi Zare Bahramabadi Institute for Research and Development in the Humanitis, SAMT, Tehran, Iran

Email:

mz.bahramabadi@gmail.com

\section{ABSTRACT}

Background and Objectives: Factors affecting one's job performance include job stress, job calling and burnout. The purpose of this study was to determine the causal relationship between job stressors, job calling and job burnout among employees of Hamadan University of Medical Sciences.

Methods: This descriptive-analytical cross-sectional study was performed on 378 non-faculty members of Hamadan University of Medical Sciences. Data were collected using Maslach Burnout Inventory, Job Stress Questionnaire (HSE-Q) and Dik's job calling. To investigate the relationship between variables, Structural Equation Modeling (SEM) method was used in AMOS version 24 software.

Results: The mean age of participants was 38.93 years. The components of job stressors and job calling had a positive and significant correlation with the components of job burnout $(P<0.05)$. The measurement model was acceptable with the collected data. Job stressors indirectly and mediate the dimensions of presence and search of job calling are related to job burnout of medical university employees. The sum of squares of multiple correlations for job burnout variable was 0.56 . This finding indicated that occupational stressors and job calling account for $52 \%$ of the variance in burnout.

Conclusion: Given the detrimental effects of burnout on employees, it is suggested that authorities reduce stressors such as the psychological and physical needs of the workplace, lack of support, job insecurity, and job calling.

Keywords: Job Stress, job calling, Job Burnout

\footnotetext{
Copyright (C) 2020, This is an original open-access article distributed under the terms of the Creative Commons Attribution-noncommercial 4.0 International License which permits copy and redistribute of the material just in noncommercial usages with proper citation.
}

\section{How to Cite This Article:}

Zare Bahramabadi M, tahmacbi B, Izadi M, Abdolhoseini H. Explaining the causal relationship between job stressors, job mission and job burnout in non academic staff of faculties of Hamadan university of medical sciences. Iran J Ergon. 2020; 7 (4):72-81 


\section{تبيين روابط على عوامل استرسزاى شغلى، رسالت شغلى و فرسودگى شغلى در كاركنان غير هيئتعلمى دانشكدههاى دانشعاه علوميزشكى همدان

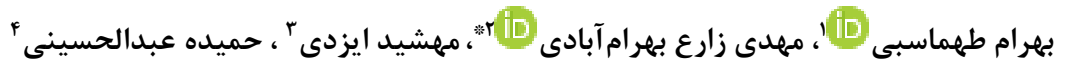

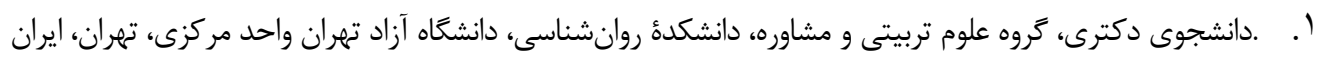

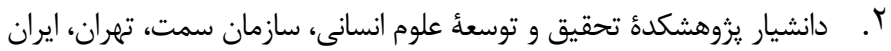

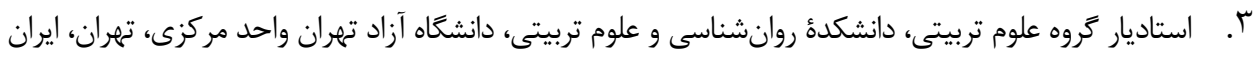

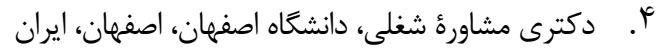

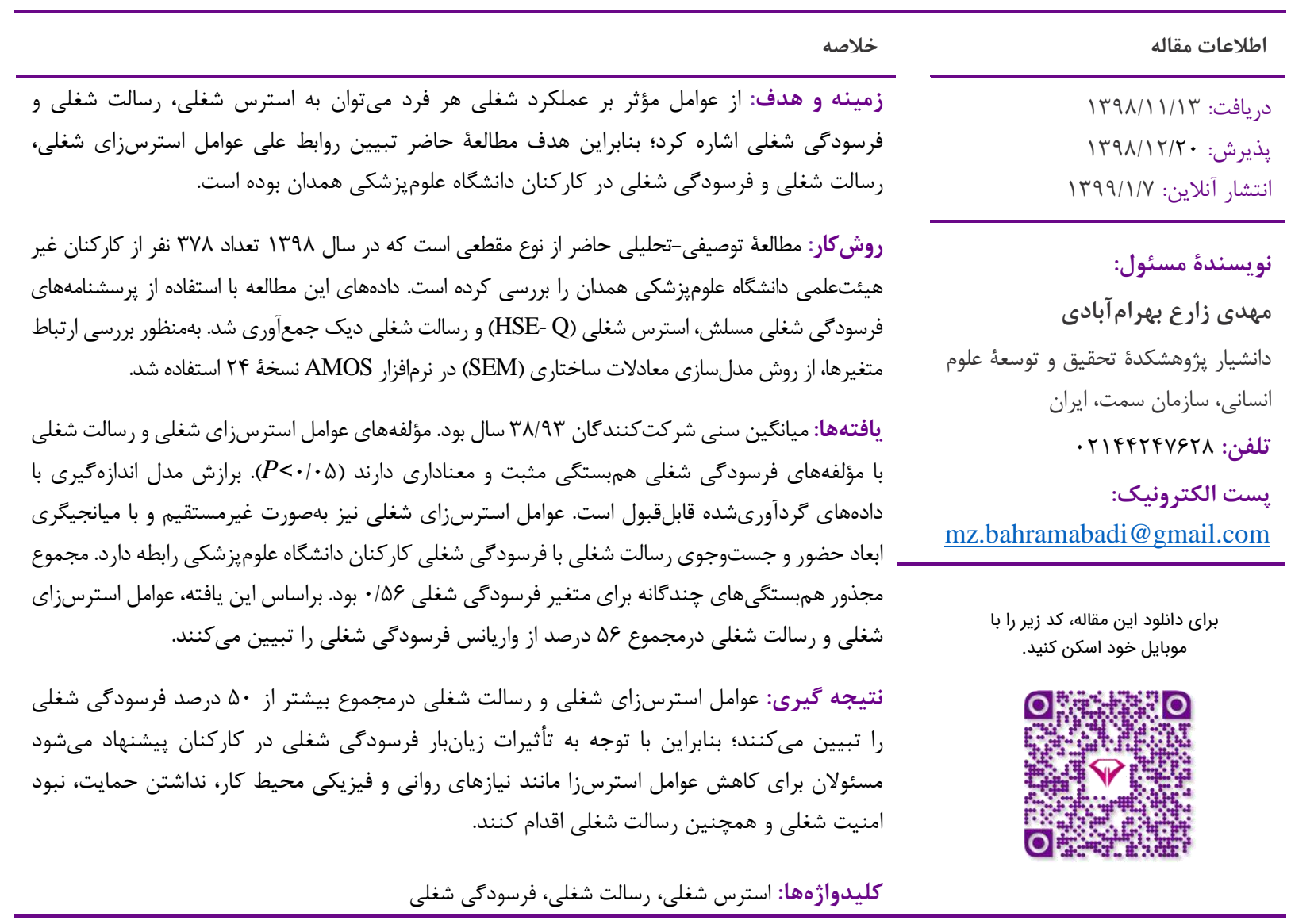

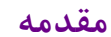

استرس شغلى است. در سالهاى اخير، استرس بيشتر از هر زمان

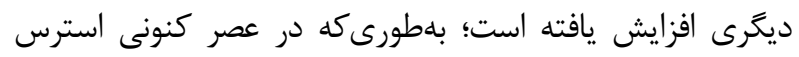

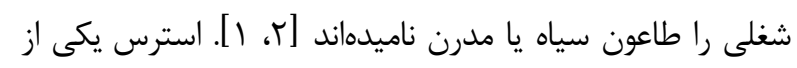

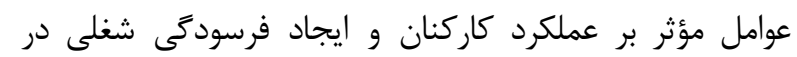

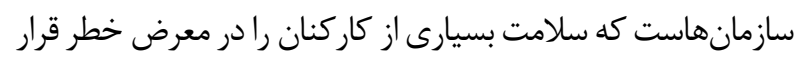

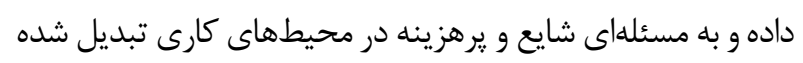

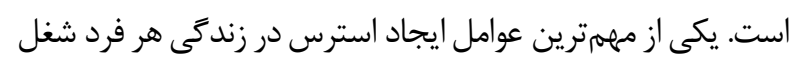

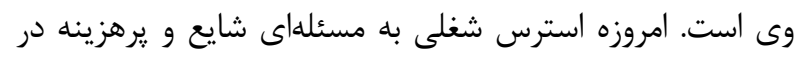

عملكرد بهينه در سازمانها بيش از آنكه در كرو تجهيزات و امكانات مناسب باشد، به نيروى انسانى وابسته است. از مشخصات سازمان بران

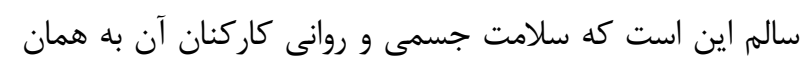

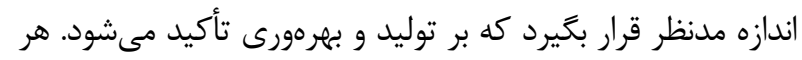

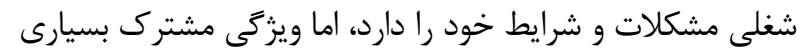

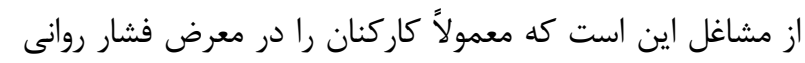

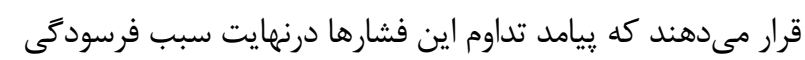

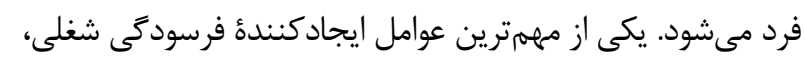




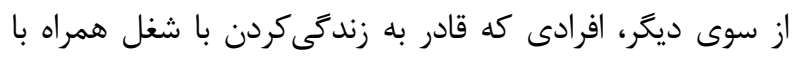

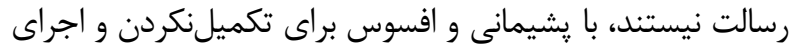

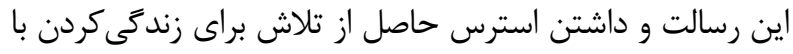

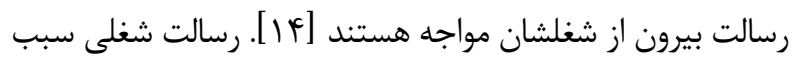
افزايش ساز كارى مسير شغلى، خودكارآمدى در تصميم كيرى مسير شغلى، رشد مسير شغلى، موفقيت روانشناختى مسير شغلى، إنى إنى

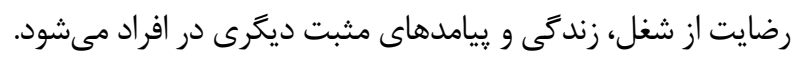
در صورتى كه نبود رسالت شغلى در محيطهاى كارى و تحصيلى مىتواند مشكلاتى مانند عدم تصميمَيرى، كاهش رشد تحصيلى

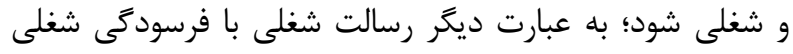

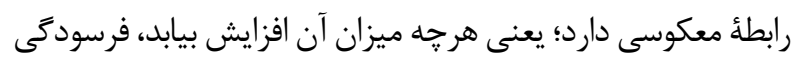
شغلى كم مىشود. از جمله يزوهشهاى انجامشده دربارة رسالت

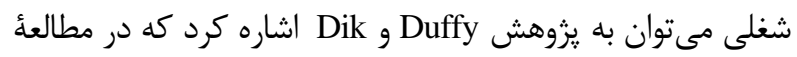

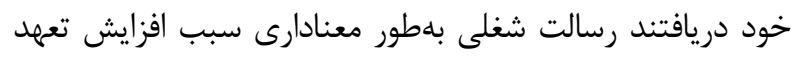
شغلى، رضايت شغلى و تعهد سازمانى مى شود. همجنين به بهعنوان

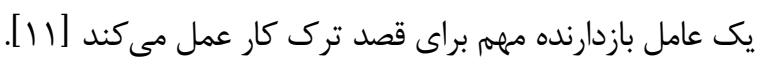

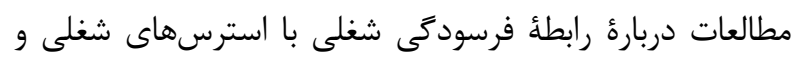
رسالت شغلى نشان مىدهد ارتباط ميان اين متغيرها بسيار

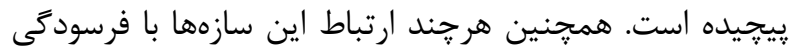
شغلى بلصورت جداكانه بررسى و مطالعه شده است، اما دربارئ

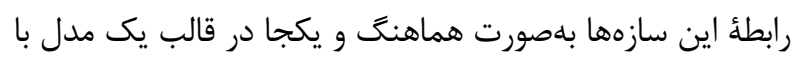
يكديكر مدنظر قرار نكرفته است؛ بنابراين با توجه به اهميت

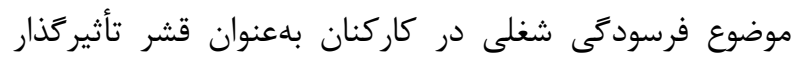

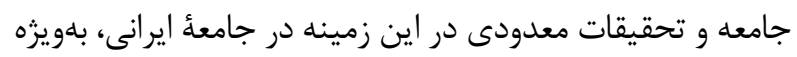

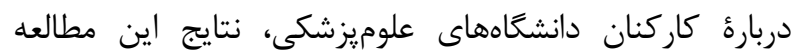

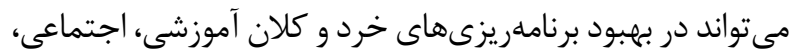

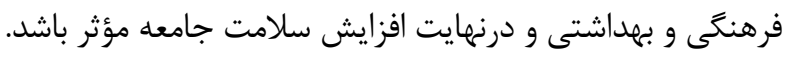

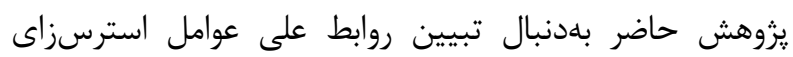
شغلى، رسالت شغلى و فرسودىى شغلى در كاركنان دانشكاه

$$
\text { علوميزشكى است. }
$$

\section{مواد و روشها - - ماد}

در مطالعأ توصيفى - تحليلى حاضر كه نوع مقطعى است و در سال

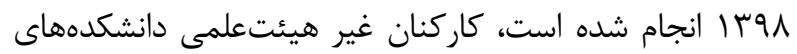

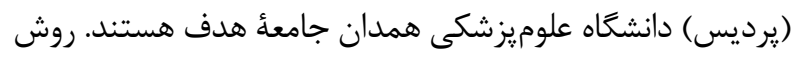
نمونه كيرى اين مطالعه سرشمارى بود؛ به صورتى كه همأ

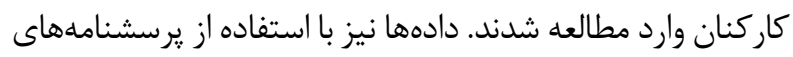
استاندارد استرس شغلى مؤسسة سلامت و ايمنى انغَلستان
محيطهاى كارى تبديل شده است ["]]. استرس به معناى تحتفشار قراركرفتن است. زمانى فرد با استرس شغلى ردائ روى

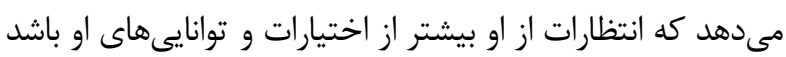

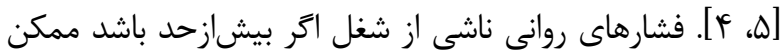

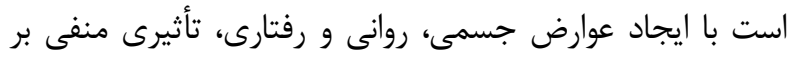
سلامت فرد داشته باشد. از سوى ديكر، وجود اين فشارها با تهديد

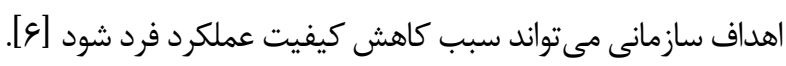
براساس مطالعات، استرس شغلى به فرسودَى، نارضايتى شغلى و

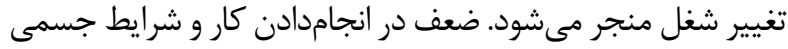
نامساعد مانند فشارخون بالا، افسردىى، اضطراب، مشكلات خواب و مصرف انواع مواد و دارو از نتايج استرس شغلى زئل زياد است، همجنين خستخى هيجانى، شخصيتزدايى و كاهش دستاورد

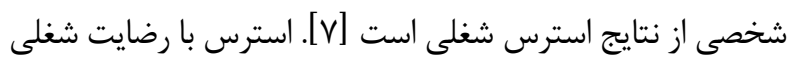

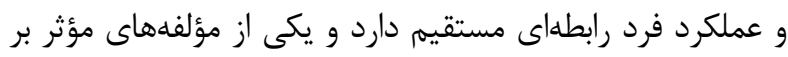
سلامت، ايمنى و آسودگى كاركنان است. هنغًامى كه كاركنان

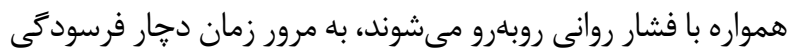

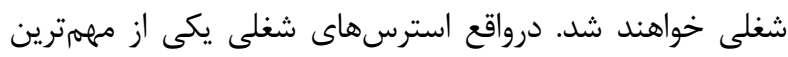
عوامل ايجادكنندة فرسودىى شغلى در طولانىمدت استى ديكر فرسودىى شغلى بيامد استرش شغلى است و نتايج مطالعات

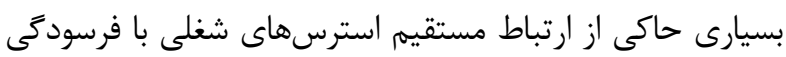

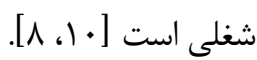

رسالت شغلى هر فرد بر عملكرد شغلى وى تأثير تذار است [1 [1]].

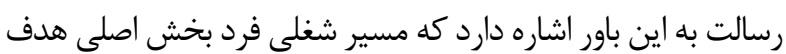
و معناى زندكى اوست. رسالت مسير شغلى براى كمك به به ديكران

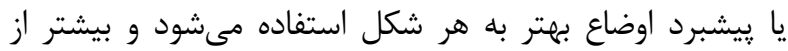

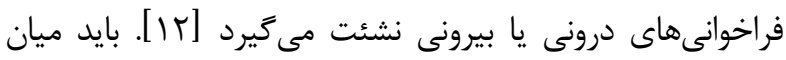

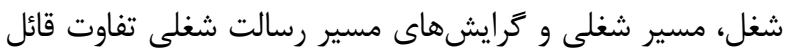

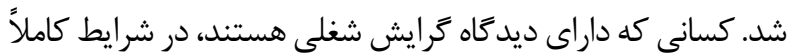

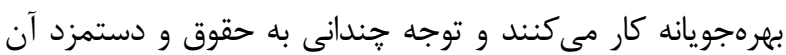

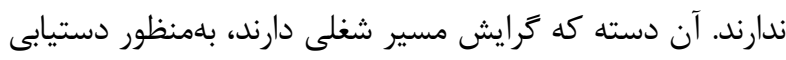

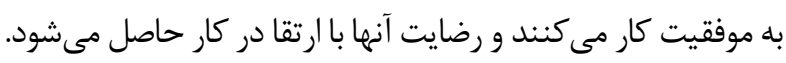
كاركنانى كه كرايش آنها رسالت شغلى است، تنها بر خود كار تمركز

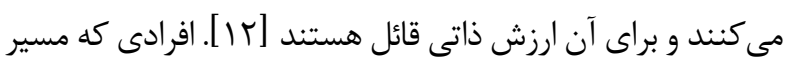

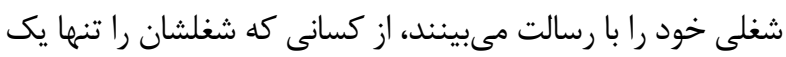
شغل يا يك مسير شغلى مىدانند، سلامتى بيشترى دارند؛ زيرا

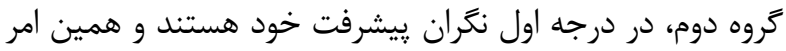

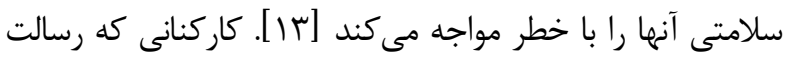

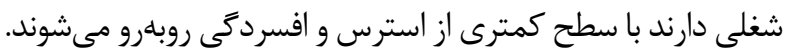


مىسنجد. نمرهگذارى هر ماده در مقياس ليكرتى از صفر (اصلاً)

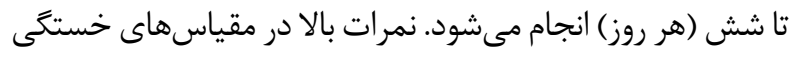
هيجانى و مسخ شخصيت و نمرءٔ بايين در مقياس احساس كفايت

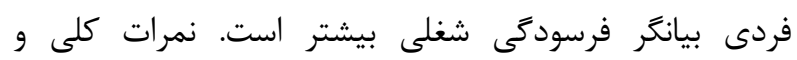

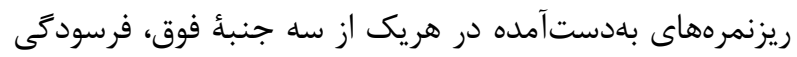

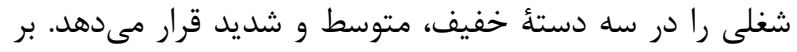

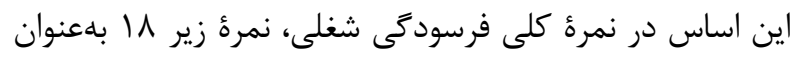

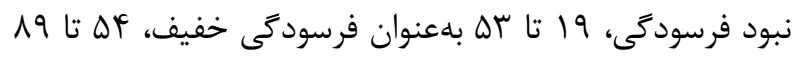

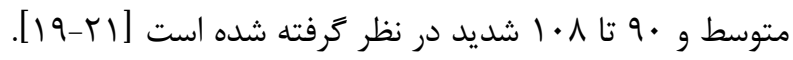

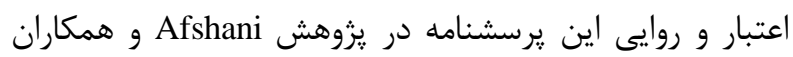

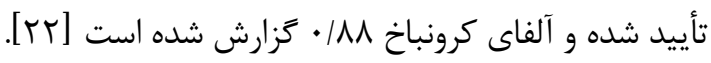

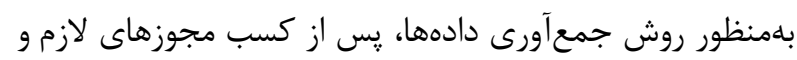

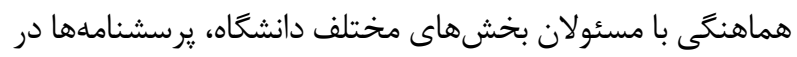

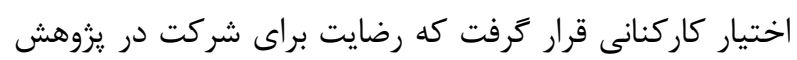

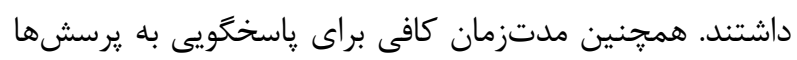

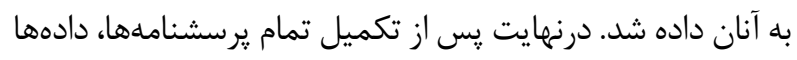

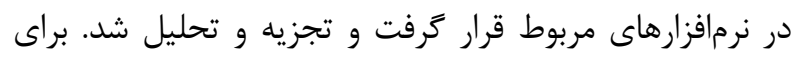

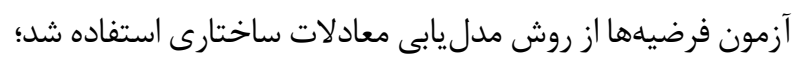

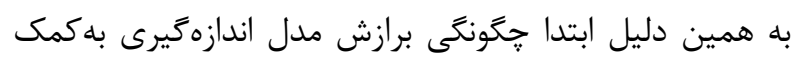

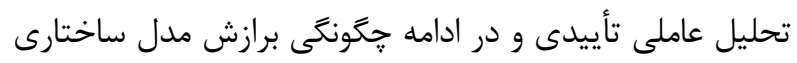

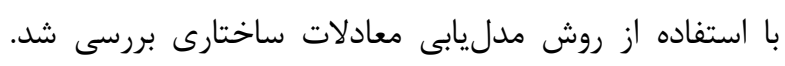

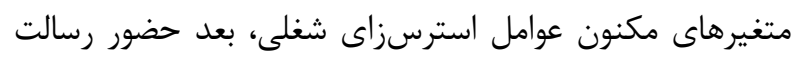

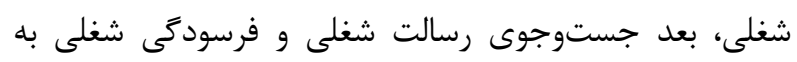

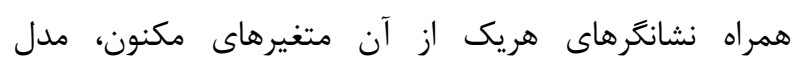

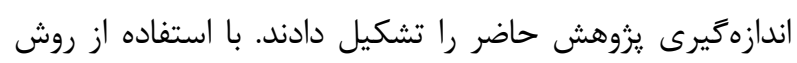

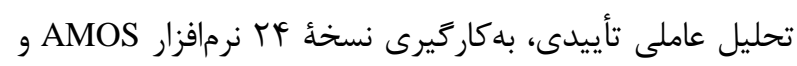

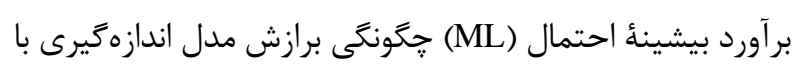

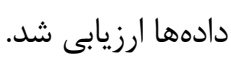

بافته ها

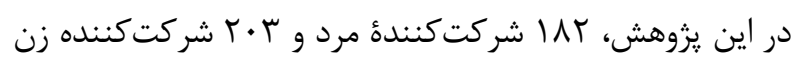

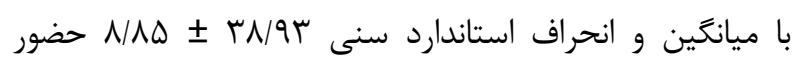

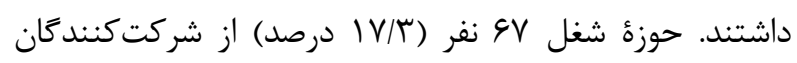

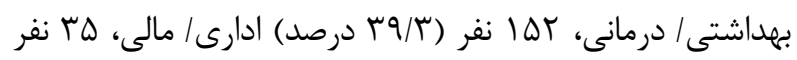

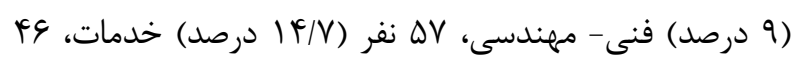

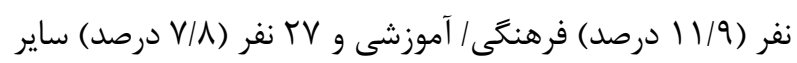
حوزهها بود. ميزان تحصيلات 9 و نفر ( شركتكنندكان دييلم و زير دييلم،
(HSE- Q) ، رسالت شغلى Dik و فرسودىى شغلى مسلش جمعآورى شد.

يرسشنامةٔ استرس شغلى موسسه سلامت و ايمنى انتخلستان (HSE):

يرسشنامة استرس شغلى HSE در مؤسسٔ سلامت و ايمنى

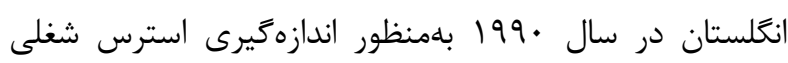

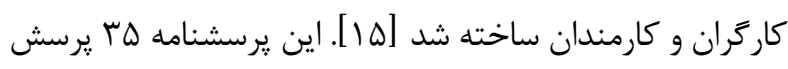
و حيطه (تقاضا، كنترل، حمايت مسئولان، حمايت همكار،

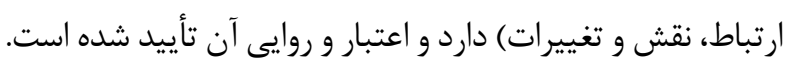

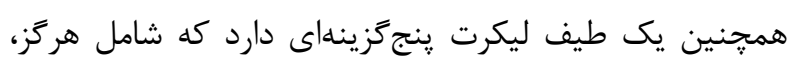

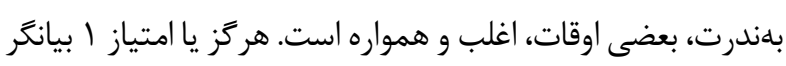

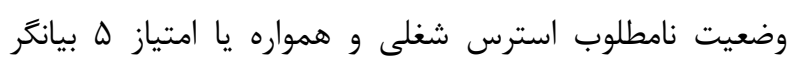

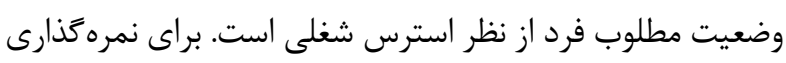

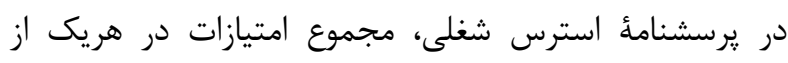

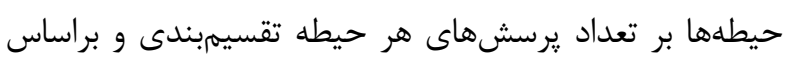

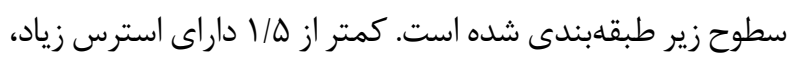

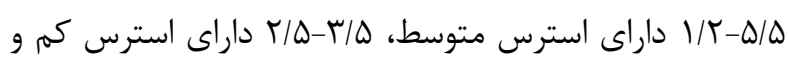

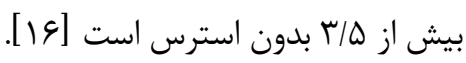

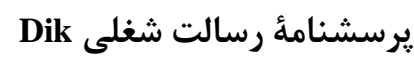

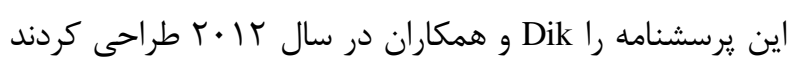

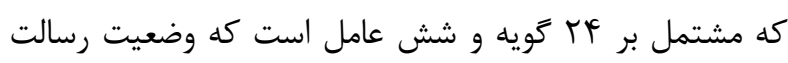

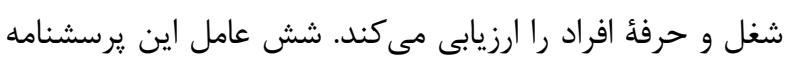

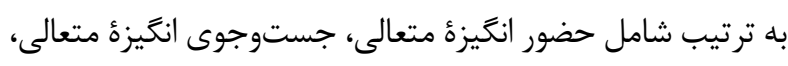

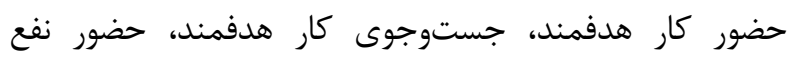

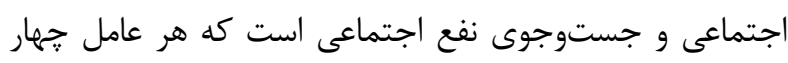

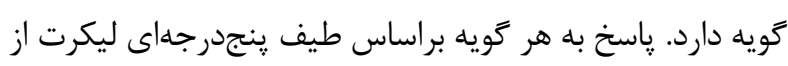

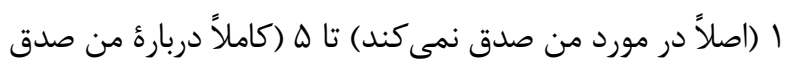

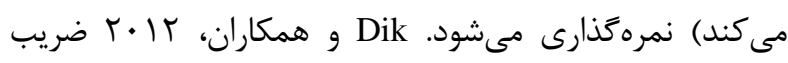

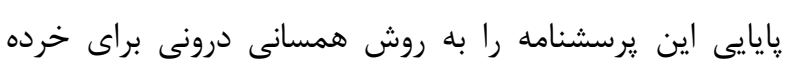

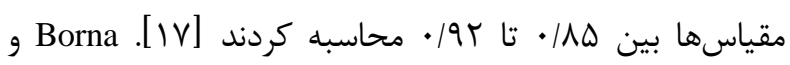

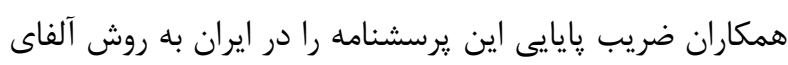

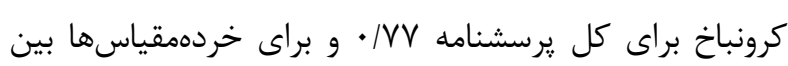

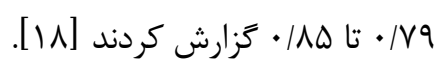

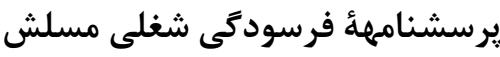

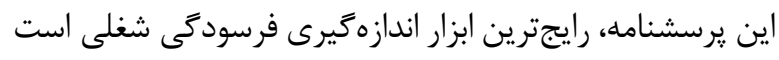

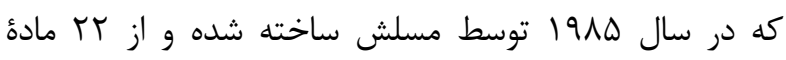

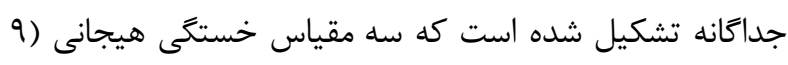

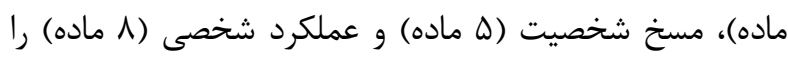




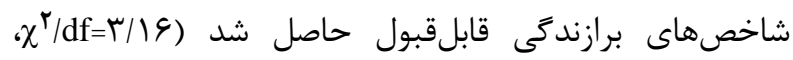
$=\cdot / \cdot V \Delta, \mathrm{GFI}=\cdot / 949$ ،AGFI $=\cdot /$ AVT CCFI $=\cdot / 911$

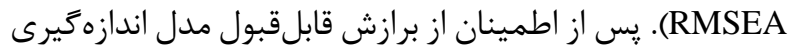

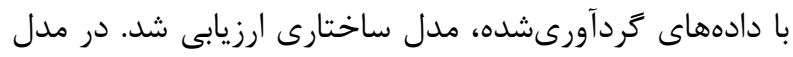

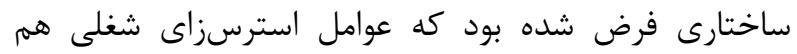

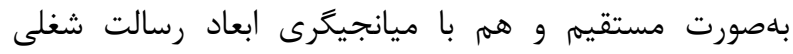

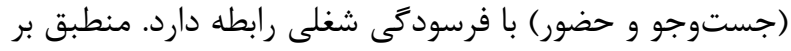

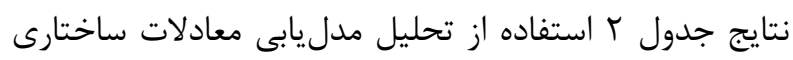
نشان مى دهد مدل ساختارى اوليه با دادهاى كردآورىشده

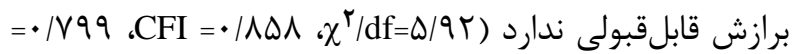

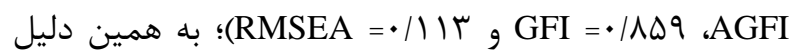
مدل ساختارى با ايجاد كوواريانس ميان خطاهاى دو متغير

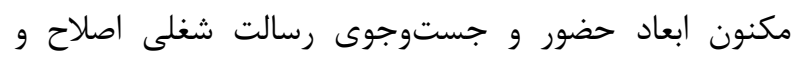
درنهايت شاخصهاى برازندكى حاصل شد كه نشان مى مدهد

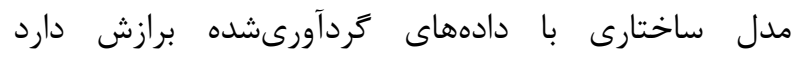

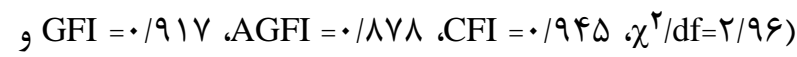
$(\operatorname{RMSEA}=\cdot / \cdot \gamma)$ جدول r ضرايب مسير كل، مستقيم و غيرمستقيم متغيرهاى

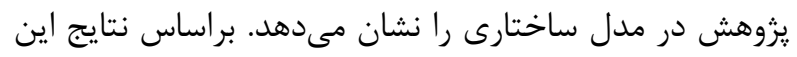

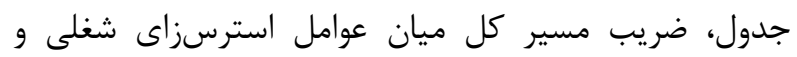
فرسودىى شغلى مثبت و در سطح

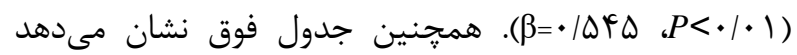

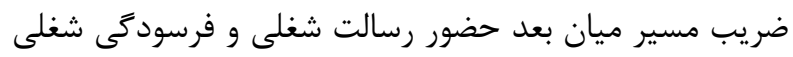

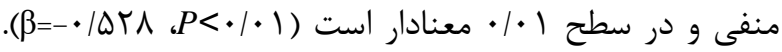
در مقابل ضريب مسير ميان بعد جستوجوى رسالت شغلى و

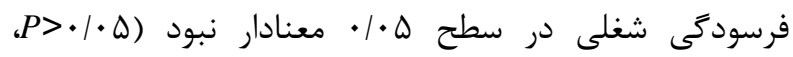

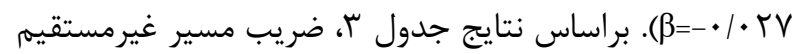

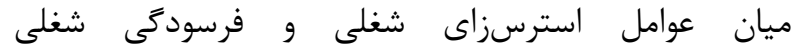

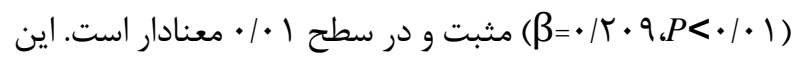

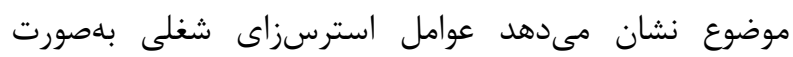
غيرمستقيم و با ميانجيكرى ابعاد حضور و جستوجوى رسالت

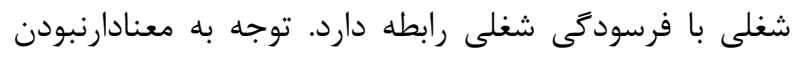

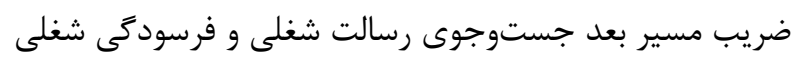
نتيجهَيرى شد كه برخلاف بعد حضور رسالت شغلى، بعد

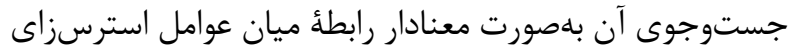
شغلى و فرسودىى شغلى را ميانجيخرى نمى كند.

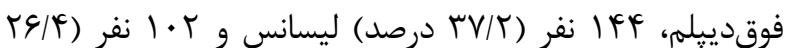

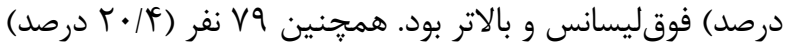

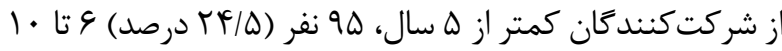

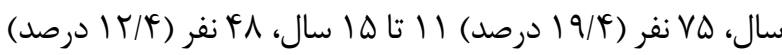

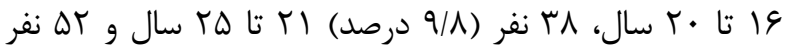

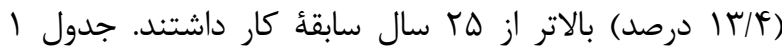

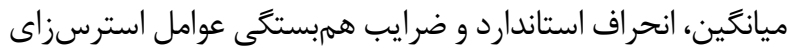
شغلى (نقش، ارتباط، حمايت مسئولان، حمايت همكاران، كنترل، تقاضا و تغييرات)، بعد حضور رسالت شغلى (انكيزهٔ متعالى، كار

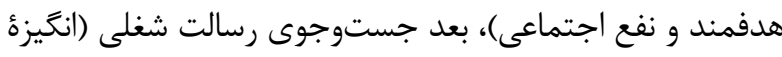

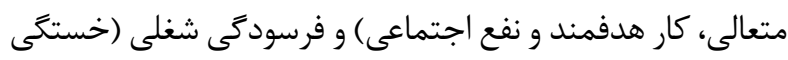
عاطفى، شخصيت زدايى و عدم موفقيت) را نشان مىدهد. در جدول ا، مؤلفههاى نقش و كنترل عوامل استرسزاى شغلى

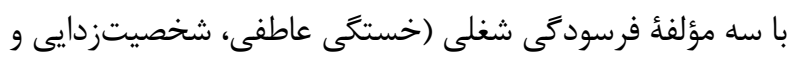

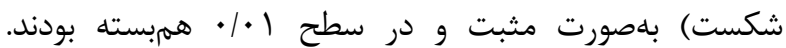
مؤلفههاى ارتباط، حمايت همكاران و تغييرات عوامل استرسزاى

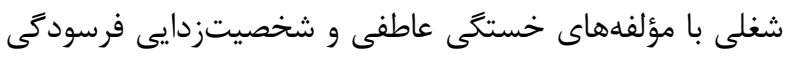

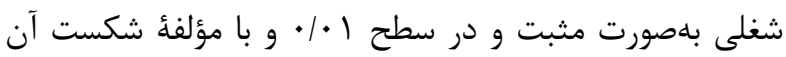

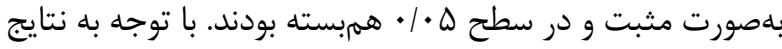
جدول 1 مؤلفههاى رسالت شغلى بلصورت منفى و در سطح معنادارى | • • با مؤلفههاى فرسودگى شغلى همبسته بودند.

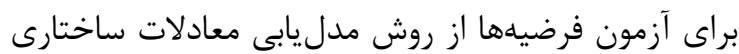

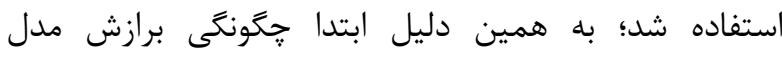

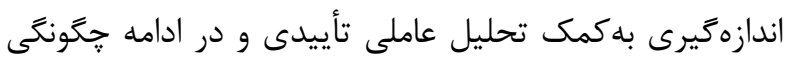
برازش مدل ساختارى بهوسيلة روش مدليابى معادلات

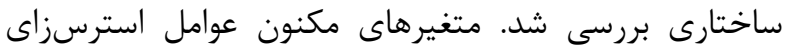

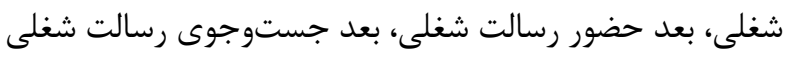

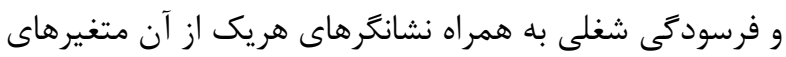

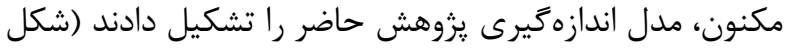

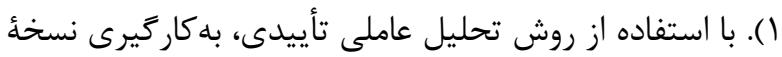

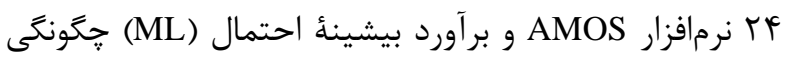

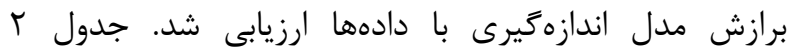

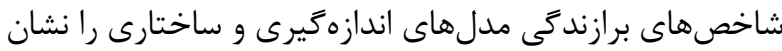

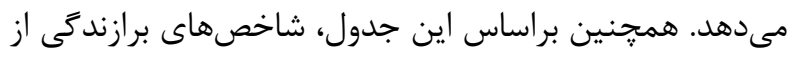

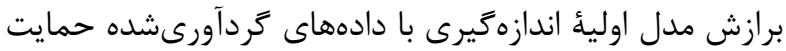

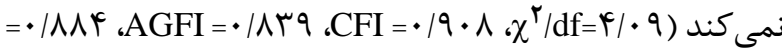
و RFI جهار مرحله با ايجاد كوواريانس ميان نشانكر ها اصلاح و درنهايت 
جدول ا. يافتهاى توصيفى (n= (nAD)

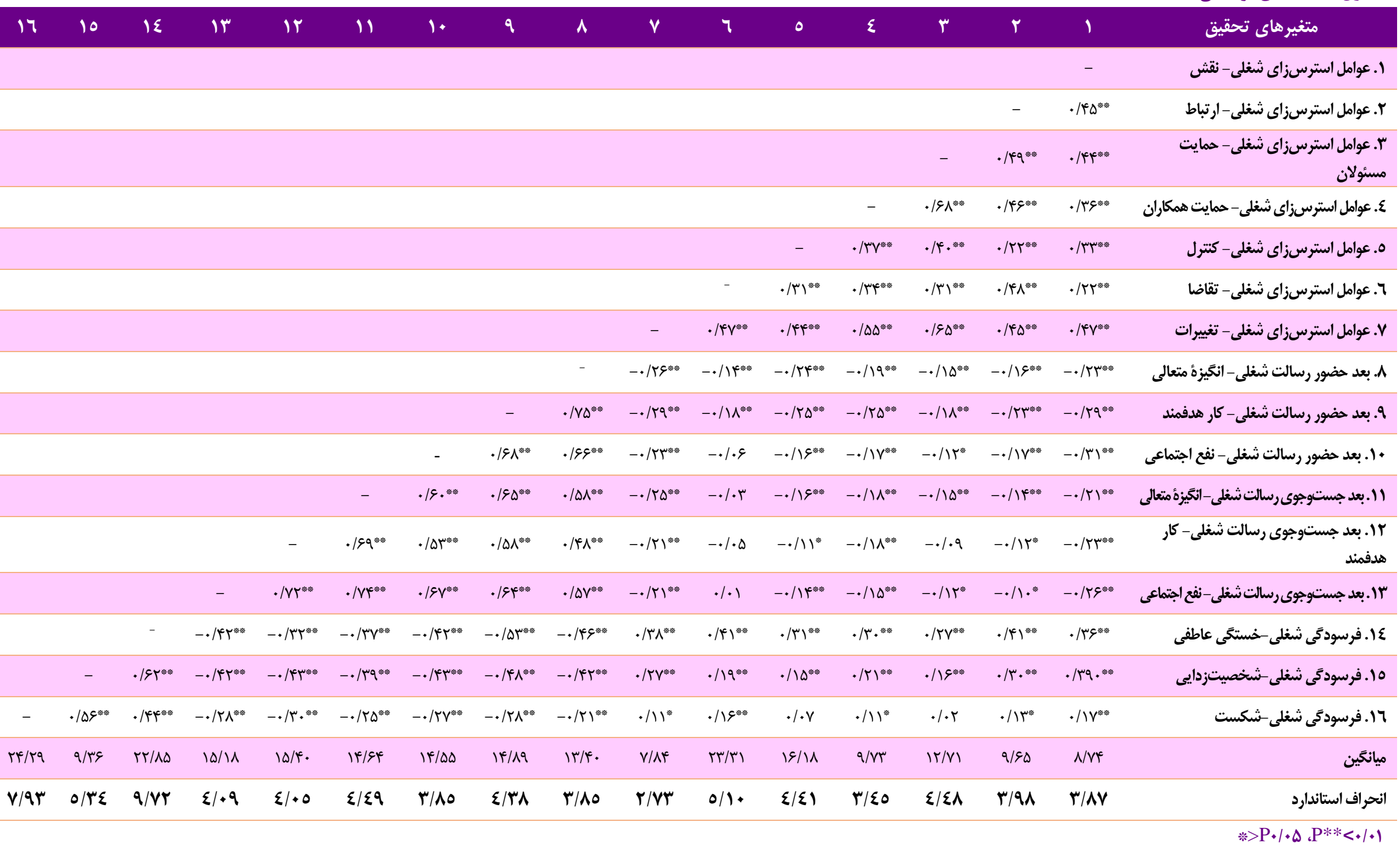




\begin{tabular}{|c|c|c|c|c|c|}
\hline \multirow{2}{*}{ نقطه برش } & \multicolumn{2}{|c|}{ مدل ساختارى } & \multicolumn{2}{|c|}{ مدل اندازهَيرى } & \multirow{2}{*}{ شاخص هاى برازندَّى } \\
\hline & مدل اصلاحشده & مدل اوليه & مدل اصلاحشده & مدل اوليه & \\
\hline- & TVN/TF & $\Delta E Y / K T$ & $r q \varepsilon / 81$ & $r . . / 94$ & مجذور كاى \\
\hline- & $9 \%$ & 90 & 94 & 91 & درجئ آزادى مدل \\
\hline كمتر از & $r / 9 q$ & D/9T & 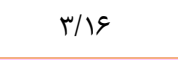 & $4 / .9$ & $\chi^{r} / \mathbf{d f}$ \\
\hline$\cdot / 9 \cdot>$ &.$/ 918$ & - / $A \Delta 9$ &.$/ 911$ & - MAF & GFI \\
\hline$\cdot / \wedge \Delta \cdot>$ & $\cdot / \Lambda \vee \Lambda$ &.$/ 199$ & . /AVT & ./Arq & AGFI \\
\hline$. / 9 .>$ &.$/ 940$ & $\cdot / A \Delta \Lambda$ & . /9rq & $\cdot / 9 \cdot 1$ & CFI \\
\hline$\cdot 1 \cdot 1<$ & $\cdot 1 \cdot v 1$ & ./11r &.$/ \cdot V \Delta$ & $\cdot 1 \cdot 19$ & RMSEA \\
\hline
\end{tabular}

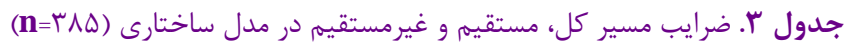

\begin{tabular}{|c|c|c|c|c|}
\hline sig & $\beta$ & S.E & $b$ & ضريب مسير \\
\hline$+1+4$ & 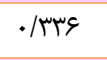 & . /TEV & $1 / T \cdot V$ & ضريب مسير مستقيم عوامل استرسزاي شغلى × فرسودَى شغلى \\
\hline - IAVA &.$- / . T V$ & . ITTD & $-\cdot / \cdot \Delta \Lambda$ & ضريب مسير بعد جستجوى رسالت شغلى † فرسودَى شغلى \\
\hline$+1++1$ & $-\cdot /$ DTA & . IFTA & $-1 / f \cdot r$ & ضريب مسير بعد حضور رسالت شغلى † فرسودَى شغلى \\
\hline$+1++1$ & $-\cdot /$ rAr & $\cdot 11 \cdot 9$ & $-\cdot / 4 \wedge 1$ & ضريب مسير عوامل استرسزاى شغلى † بعد جستجوى رسالت شغلى \\
\hline$+1++1$ & $-\cdot /$ r & $.1 \cdot 98$ & $-\cdot / 01 \Lambda$ & ضريب مسير عوامل استرسزاى شغلى † بعد حضور رسالت شغلى \\
\hline$+1++1$ & $\cdot / 4 \cdot 9$ & $\cdot / 194$ & - /Veq & ضريب مسير غيرمستقيم عوامل استرسزاى شغلى † فرسودكى شغلى \\
\hline$+1++1$ & $+10 \leqslant 0$ & $\cdot / 4 a t$ & $1 / 907$ & ضريب مسير كل عوامل استرسزاى شغلى † فرسودَى شغلى \\
\hline
\end{tabular}

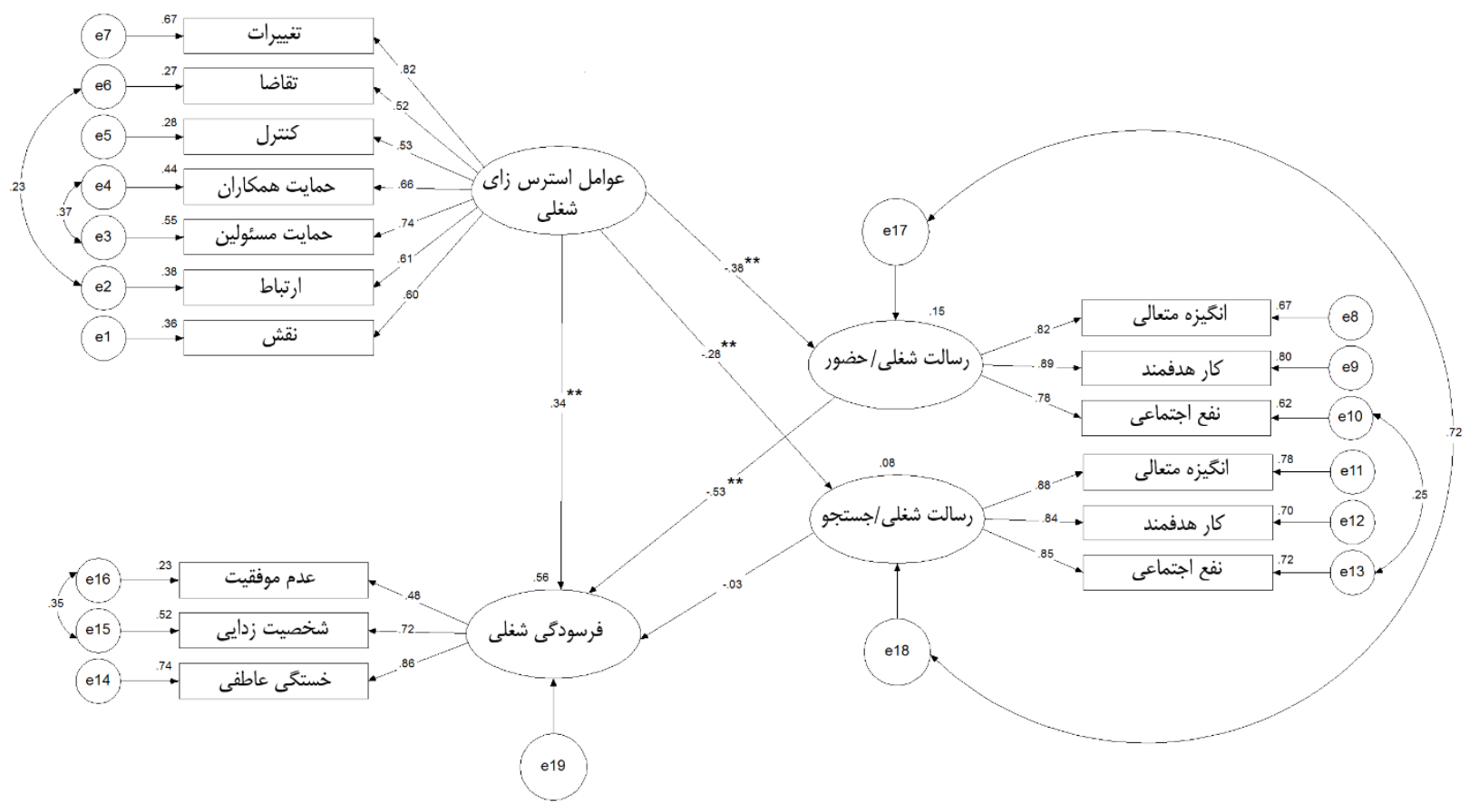

شكل ا. مدل كلى يزوهش و ضرايب مسير متغيرها براساس نمرههاى استاندارد 
ييشبينى مى كند، اما Borna و همكاران مطالعهاى با هدف

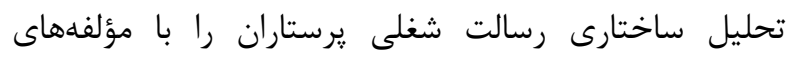

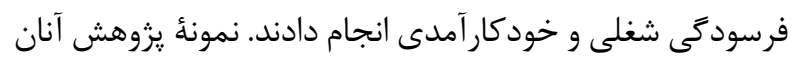

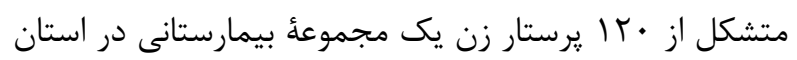

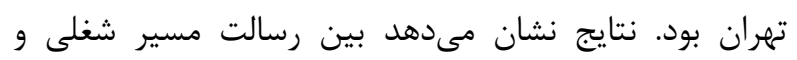

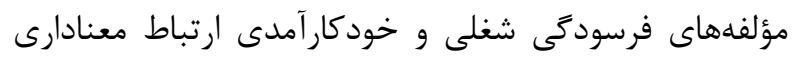

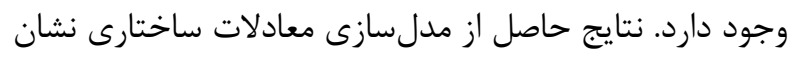

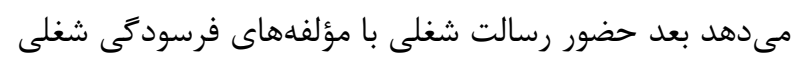

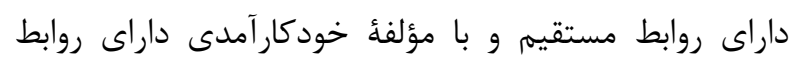

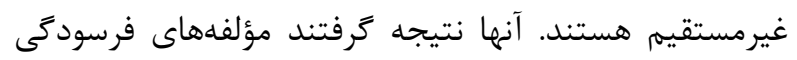

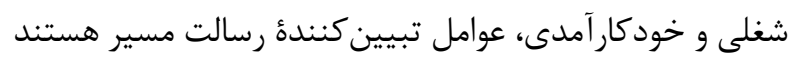

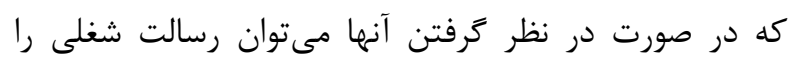

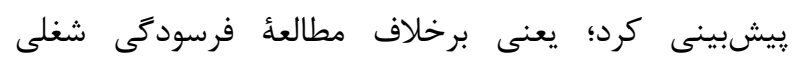

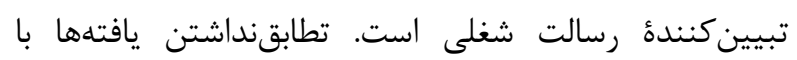

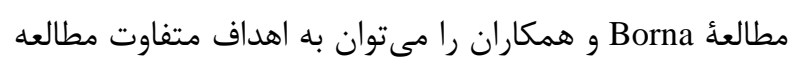

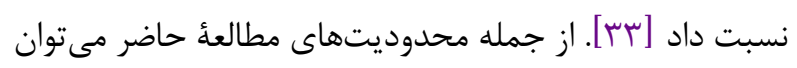

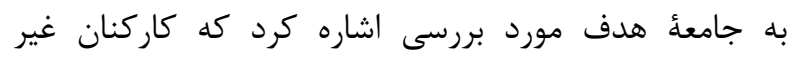

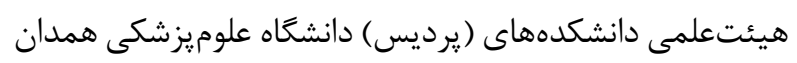

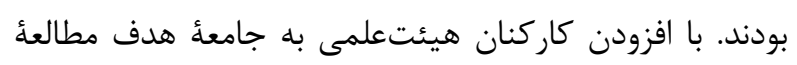

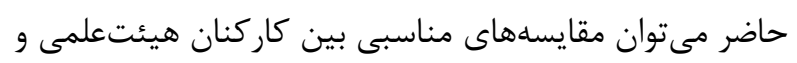
غير هيئت علمى داشت.

\section{نتيجه كيرى}

عوامل استرسزاى شغلى و رسالت شغلى درمجموع بيشتر

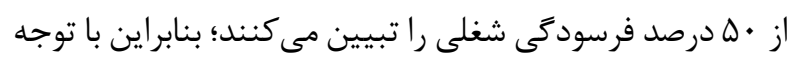

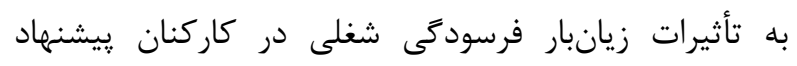

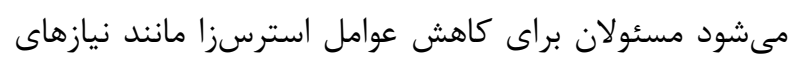

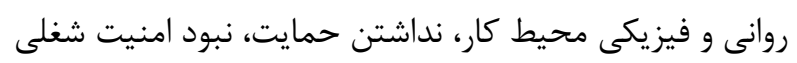
و همجنين رسالت شغلى اقدام كنند.

تقدير و تشكر

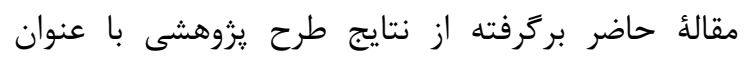

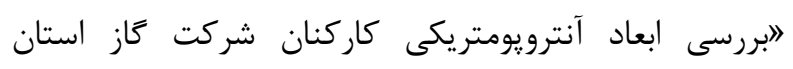

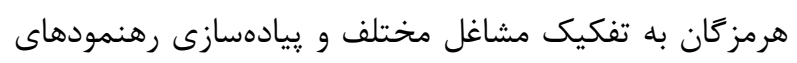

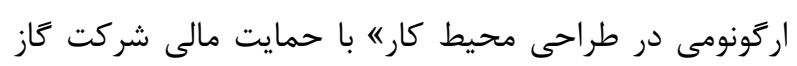
استان هرمزگان است.
شكل 1 مدل ساختارى يزوهش را در تبيين روابط عوامل

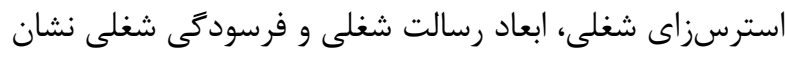

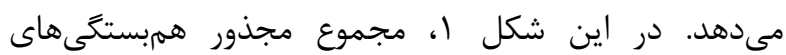

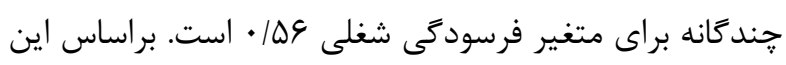

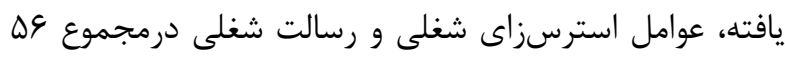
درصد از واريانس فرسودىى شغلى را تبيين مى كنيند.

\section{بحث}

نزديكتر ين با توجه به نتايج بهدستآمده در مطالعهُ حاضر،

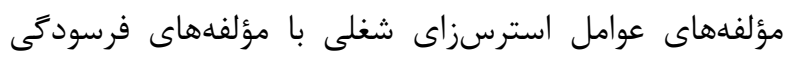

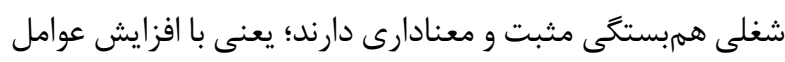

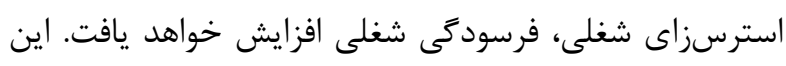
يافتهها با نتايج مطالعُ حيدرى و همكاران، 'Zargar Balaye 9 Rahmani ‘Hajloo Daneshvarg Jame همكاران، Shakerinia و همكاران، عبدى و همكاران، Watson

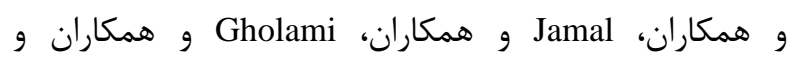
Hoseinian

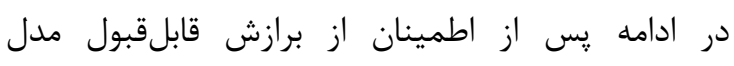

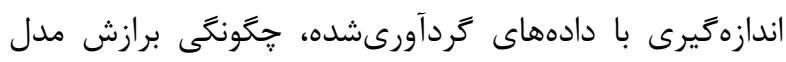

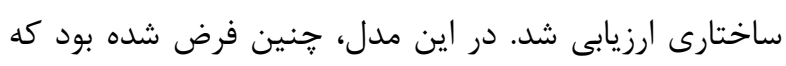

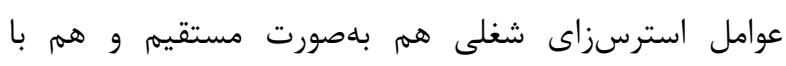

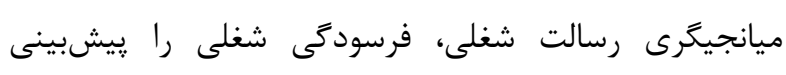

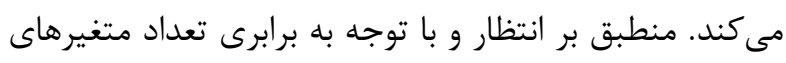

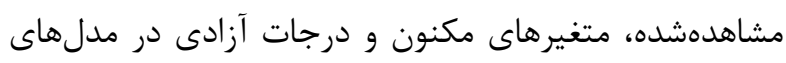

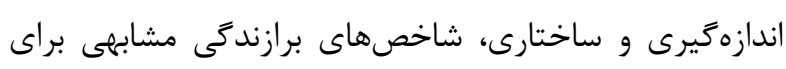

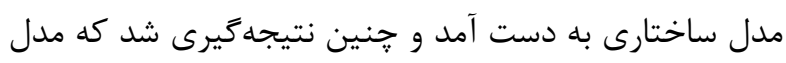

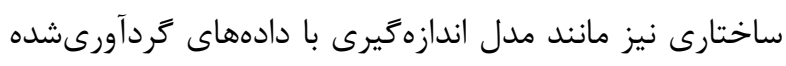

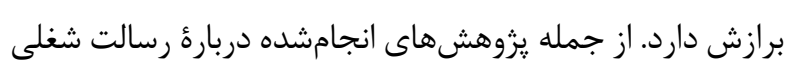

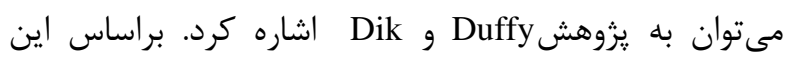

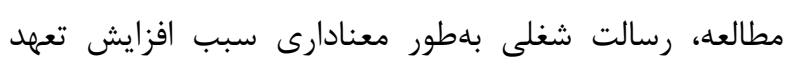

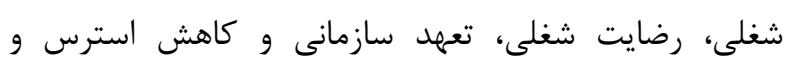

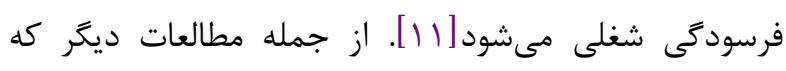

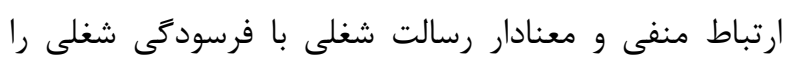

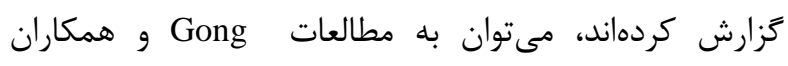

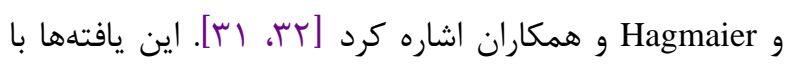
نتايج حاصل از مطالعه حاضر نيز همخوانى دارد.

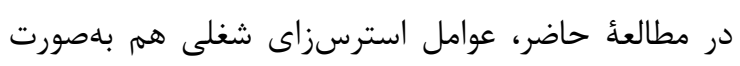

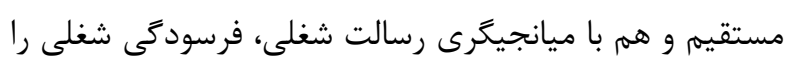




$$
\text { تعارض منافع }
$$

$$
\begin{aligned}
& \text { منابع مالى } \\
& \text { منابع مالى اين كار تحقيقاتى توسط دانشكدة روانشناسى و }
\end{aligned}
$$

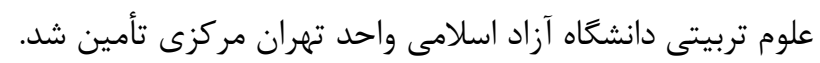

\section{References}

1. Karchani M, Ebrahimi A. The Survey of occupational stress, effective factors and relation it with fields human errors on staff of hospital. Iranian Safety Science and Technology Journal. 2015;2(4):49-58.

2. Gerber M, Pühse U. "Don't crack under pressure!"-Do leisure time physical activity and self-esteem moderate the relationship between school-based stress and psychosomatic complaints? Journal of psychosomatic research. 2008;65(4):363-9. [DOI:10.1016/j.jpsychores.2008.06.012] [PMID]

3. Hoboubi N, Choobineh A, Ghanavati FK, Keshavarzi S, Hosseini AA. The impact of job stress and job satisfaction on workforce productivity in an Iranian petrochemical industry. Safety and health at work. 2017;8(1):67-71. [DOI:10.1016/j.shaw.2016.07.002] [PMID] [PMCID]

4. Seaward BL. Managing stress: Jones \& Bartlett Learning; 2017.

5. Mesler R, Capobianco M. Psychosocial factors associated with job stress. Stress news. 2001;13(4):22-4.

6. Lambert EG, Qureshi H, Frank J, Klahm C, Smith B. Job stress, job involvement, job satisfaction, and organizational commitment and their associations with job burnout among Indian police officers: A research note. Journal of Police and Criminal Psychology. 2018;33(2):85-99. [DOI:10.1007/s11896-017-9236-y]

7. Quick JC, Henderson DF. Occupational stress: Preventing suffering, enhancing wellbeing. International journal of environmental research and public health. 2016;13(5):450-459. [DOI:10.3390/ijerph13050459] [PMID] [PMCID]

8. Zargar Balaye Jame S, Daneshvar A. The Relationship Between Job Burnout and Its Dimensions with Job Stress in Isfahan University of Medical Sciences in 2018. Journal of Hospital. 2018;17(3):87-99.

9. Garrosa E, Rainho C, Moreno-Jimenez B, Monteiro MJ. The relationship between job stressors, hardy personality, coping resources and burnout in a sample of nurses: A correlational study at two time points. International journal of nursing studies. 2010;47(2):205-15. [DOI:10.1016/j.ijnurstu.2009.05.014] [PMID]

$$
\begin{aligned}
& \text { تشكر و قدردانى } \\
& \text { اين مطالعه در قالب پاياننامهٔ دكترى در دانشكدء } \\
& \text { روانشناسى و علوم تربيتى دانشعاه آزاد اسلامى واحد تهران } \\
& \text { مركزى انجام شد؛ از اينرو از همهُ كاركنانى كه در اين مطالعه }
\end{aligned}
$$

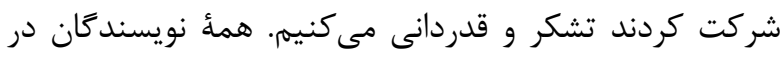

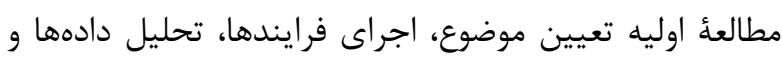

$$
\begin{aligned}
& \text { نَارش گزارش نهايى مشاركت داشتهاند. }
\end{aligned}
$$

10. Farahani SB, Fotovat B, Abadzadeh P, Hemati A. Study of the role of work ethic on job stress and job burnout (Case Study: Teachers of Physical Education in Tehran Secondary Schools). Journal of Organizational Behavior Management Studies in Sport. 2018;5(1):43-51.

11. Duffy RD, Dik BJ. Research on calling: What have we learned and where are we going? Journal of Vocational Behavior. 2013;83(3):428-36. [DOI:10.1016/j.jvb.2013.06.006]

12. Dik BJ, Duffy RD. Calling and vocation at work: Definitions and prospects for research and practice. The counseling psychologist. 2009;37(3):424-50. [DOI:10.1177/0011000008316430]

13. Duffy RD, Sedlacek WE. The presence of and search for a calling: Connections to career development. Journal of Vocational Behavior. 2007;70(3):590-601. [DOI:10.1016/j.jvb.2007.03.007]

14. Berg JM, Grant AM, Johnson V. When callings are calling: Crafting work and leisure in pursuit of unanswered occupational callings. Organization science. 2010;21(5):973-94. [DOI:10.1287/orsc. 1090.0497]

15. Cousins* R, Mackay CJ, Clarke SD, Kelly C, Kelly PJ, McCaig RH. 'Management standards' work-related stress in the UK: Practical development. Work \& Stress. 2004;18(2):113-36. [DOI:10.1080/02678370410001734322]

16. Azad Me, Gholami Fm. Reliability and validity assessment for the HSE job stress questionnaire. 2011.

17. Dik BJ, Eldridge BM, Steger MF, Duffy RD. Development and validation of the calling and vocation questionnaire (CVQ) and brief calling scale (BCS). Journal of career assessment. 2012;20(3):242-63. [DOI: $10.1177 / 1069072711434410]$

18. Borna M, Pordelan N, Khalijian S, Seyedtalebi M. Interactive Structure And Validity Of The Persian Version Of Calling Scale Midst Medical Students. 2015.

19. Maslach C, Schaufeli WB, Leiter MP. Job burnout. Annual review of psychology. 2001;52(1):397-422. [DOI:10.1146/annurev.psych.52.1.397] [PMID]

20. Maslach C, Leiter MP. Understanding the burnout experience: recent research and its implications for psychiatry. World psychiatry. 2016;15(2):103-11. [DOI:10.1002/wps.20311] [PMID] [PMCID] 
21. Maslach C, Jackson S, Leiter M. MBI: Maslach burnout inventory: CPP. Incorporated Sunnyvale (CA). 1996.

22. Afshani SA, Jahanbakhsh Ganjeh S, Jahanbakhsh Ganjeh $\mathrm{S}$. The role of organizational commitment, social support, general health and job satisfaction in predicting burnout among the staff of Social security organization at Kohgiluyeh and Boyer Ahmad. Knowledge \& Research in Applied Psychology. 2017;18(2):72-81.

23. Hajloo N. The Relationship Of Staffs'job Stress, Burnout, And Life Quality To Organizational Climate Satisfaction At Mohaghegh Ardabili University. 2012.

24. Rahmani F, Behshid M, Zamanzadeh V, Rahmani F. Relationship between general health, occupational stress and burnout in critical care nurses of Tabriz teaching hospitals. 2010 .

25. Shakerinia I, Mohammadpour M. Relationship between job stress and resiliency with occupational burnout among nurses. J Kermanshah Univ Med Sci. 2010;14(2):161-9.

26. Gashmard R, Bagherzadeh R, Pouladi S, Akaberian S. Burnout and its related demographic factors among the medical staff working in hospitals associated with Bushehr University of Medical Sciences. Puerto Rico health sciences journal. 2015;34(4):208-14.

27. Watson R, Deary I, Thompson D, Li G. A study of stress and burnout in nursing students in Hong Kong: a questionnaire survey. International journal of nursing studies. 2008:45(10):1534-42. [DOI:10.1016/j.ijnurstu.2007.11.003] [PMID]

28. Jamal M, Baba VV. Job stress and burnout among Canadian managers and nurses: an empirical examination. Canadian journal of public health. 2000;91(6):454-8. [DOI:10.1007/BF03404828] [PMID] [PMCID]

29. Gholami T, Heidari Pahlavian A, Akbarzadeh M, Motamedzade M, Heidari Moghadam R. A structural equation modeling study of job stress and musculoskeletal disorders. Iranian Journal of Ergonomics. 2015;3(3):51-64.

30. GolMohammadian M, Sajjadi SN, Salimi H. The Role of Psychological Capital and Organizational Citizenship Behavior in Predicting Job Satisfaction of Exceptional Elementary School's Teachers. Exceptional Education Journal. 2016;3(140):5-12.
31. Alipour A, Sarami Forushani G, Agha Alikhani A, Akhundi N. Evaluation of the effectiveness of psychological capital intervention of luthans on job burnout in the experts working in Iran Khodro Diesel company. Occupational Medicine Quarterly Journal. 2013;5(3):30-41.

32. Luthans F, Avey JB, Avolio BJ, Peterson SJ. The developmnt and resulting performance impact of positive psychological capital. Human resource development quarterly. 2010;21(1):41-67. [DOI:10.1002/hrdq.20034]

33. Pasha N, Shakerinia I, Abolghasemi A. The Relationship of Organiztional Citizenship Behaviors, Organizational Spirituality and Social Capital with Employees' Counterproductive Behaviors. Psychology. 2017;4(1):91111. 